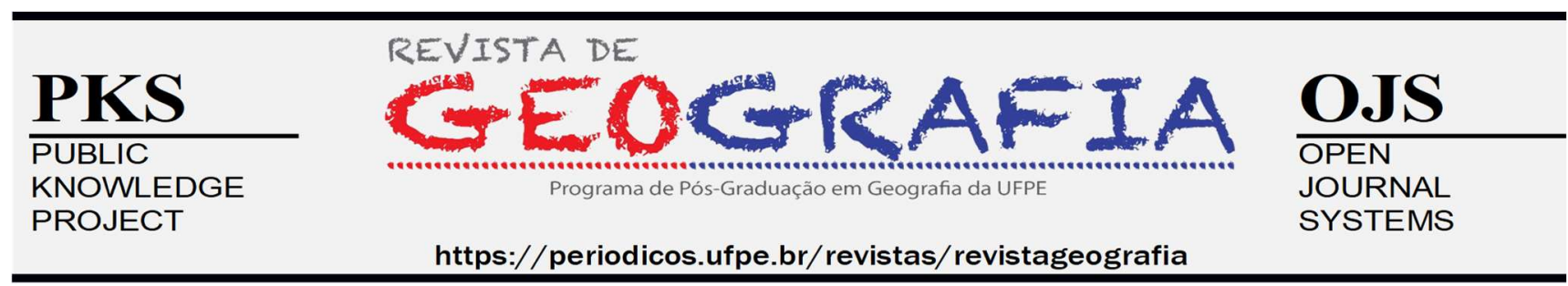

\title{
ANÁLISE DOS FLUXOS SUPERFICIAIS EM RELEVO DE CUESTA E SUA INTERAÇÃO COM FEIÇÕES EROSIVAS LINEARES
}

\author{
Estêvão Botura Stefanuto ${ }^{1}$, Cenira Maria Lupinacci ${ }^{2}$
}

\begin{abstract}
${ }^{1}$ Doutorando no Programa de Pós-Graduação em Geografia (PPGG) da Universidade Estadual Paulista (UNESP) Campus de Rio Claro. E-mail: estevao1508@hotmail.com. ORCID: https://orcid.org/0000-0001-6580-2563

${ }^{2}$ Professora do Departamento de Geografia e Planejamento Ambiental (DGPA) da Universidade Estadual Paulista (UNESP) Campus de Rio Claro. E-mail: cenira.lupinacci@unesp.br. ORCID: https://orcid.org/0000-0002-4732-1421
\end{abstract}

Artigo recebido em 28/08/2020 e aceito em 14/12/2020

\begin{abstract}
RESUMO
Os fluxos acumulados de superfície em ambientes tropicais representam variável importante para o entendimento da erosão dos solos, principalmente em condições geomorfológicas onde a declividade pode dinamizá-los. Neste sentido, o objetivo deste artigo é analisar a interação dos fluxos acumulados de superfície com as feições erosivas lineares, a declividade e o uso da terra em um setor de domínio de Cuestas. Para tal, selecionou-se uma bacia hidrográfica localizada na porção central do relevo cuestiforme paulista (Analândia-SP), caracterizada por intenso uso agrícola. Assim, desenvolveu-se uma Carta de Fluxo Acumulado do Escoamento Superficial, sendo analisada a fim de identificar a área de ocorrência de feições erosivas em relação a cada classe de fluxo. Tais dados foram complementados com informações referentes ao declive e ao uso e ocupação da terra. Desta forma, se identificou: a) fluxos acumulados de superfície no domínio de cuestas são muito elevados em relação aos dados apresentados na bibliografia; b) sulcos erosivos e ravinas ocorrem em diversas classes de fluxo, o que se deve a interferência da declividade e do uso da terra; c) voçorocas se apresentam concentradas na segunda maior classe de fluxo, fato que deve ser considerado na busca por medidas de contenção erosiva.
\end{abstract}

Palavras-chave: Geomorfologia; fluxo acumulado elevado; erosão.

\section{SURFACE FLOWS ANALYSIS IN CUESTA RELIEF AND ITS INTERACTION WITH LINEAR EROSIVE FEATURES}

\begin{abstract}
The accumulated surface flows in tropical environments represent an important variable for the soil erosion understanding, especially in geomorphological conditions where the slope can dynamize them. In this sense, the objective of this article is to analyze the interaction of accumulated surface flows with linear erosive features, slope and land use in the Cuestas domain. For this purpose, a catchment located in the central portion of the paulista cuesta relief (Analândia - SP) was selected, characterized by intense agricultural use. Thus, an Accumulated Flow Map of Surface Runoff was developed, being analyzed in order to identify the area of occurrence of erosive features in relation to each flow class. These data were complemented with information regarding the slope and the land use and occupation. Thus, identified: a) accumulated surface flows in the Cuesta domain are very high in relation to the data presented in the bibliography; b) rills erosion and ravines occur in the different flow classes, which is due to the interference of slope and land use; c) gullies are concentrated in the second largest flow class, a fact that should be considered in the search for erosion containment measures.
\end{abstract}

Keywords: Geomorphology; high accumulated flow; erosion. 


\section{ANÁLISIS DE FLUJOS SUPERFICIALES EN RELIEVE DE CUESTA Y SU INTERACCIÓN CON FORMAS EROSIVAS LINEALES}

\section{RESUMEN}

Los flujos superficiales acumulados en ambientes tropicales representan una variable importante para comprender la erosión del suelo, especialmente en condiciones geomorfológicas donde la declividad puede dinamizarlos. En este sentido, el objetivo de este artículo es analizar la interacción de los flujos superficiales acumulados con las formas erosivas lineales, la declividad y el uso del suelo en un sector del dominio Cuestas. Para eso, se seleccionó una cuenca hidrográfica ubicada en la porción central del relieve cuestiforme de São Paulo (Analândia-SP), caracterizada por un intenso uso agrícola. Por lo tanto, se desarrolló un Mapa de Flujo Acumulado de Escorrentía Superficial, siendo analizado con el fin de identificar la área de ocurrencia de formas erosivas en relación con cada clase de flujo. Estos datos se complementaron con información sobre la declividad y el uso y ocupación del suelo. Así, se identificó: a) los flujos superficiales acumulados en el dominio de cuestas son muy altos en relación a los datos presentados en la bibliografía; b) los surcos erosivos y las quebradas ocurren en diferentes clases de flujo, lo que se debe a la interferencia de la declividad y el uso de la tierra; c) las quebradas se concentran en la segunda clase de flujo más grande, hecho que debe ser considerado en la búsqueda de medidas de contención de la erosión.

Palabras clave: Geomorfología; alto flujo acumulado; erosión.

\section{INTRODUÇÃO}

Dados da European Academies Sciencie Advisory Council - EASAC (2018a) evidenciam um aumento significativo na intensidade dos eventos pluviométricos mundiais nos últimos 30 anos, fato que a própria organização julga como preocupante a partir de uma perspectiva de degradação dos solos (EASAC, 2018b). Outra entidade que manifesta preocupação é a Food and Agriculture Organization (FAO, 2015), a qual aponta que a erosão dos solos do globo pela água das chuvas encontra-se entre 20 e $30 \mathrm{Gt}^{\text {ano- }}{ }^{1}$ em média. Com isso, compreende-se que as águas pluviais atuam sobre a superfície do globo de forma significativa, ocorrendo, dentre outros processos, através do escoamento superficial, o qual pode acontecer de forma concentrada ou difusa (GUERRA; GUERRA, 2010).

Neste sentido, a ação das águas das chuvas sobre a superfície terrestre e suas diversas características devem ser analisadas, uma vez que há múltiplos fatores que interferem na sua atuação, como apontam as pesquisas. Para Thomas et al. (2018), por exemplo, cabe atenção a perda de solos em sub-bacias submetidas a condições climáticas semiáridas, pois essas apresentam cobertura vegetal reduzida, principalmente no início da estação chuvosa, podendo ainda tais setores registrarem eventos isolados de chuvas de alta intensidade. Ainda, Marzen et al. (2017) destacam que a atuação conjunta do vento e da chuva (wind-driven rain - WDR) apresenta maior potencial erosivo e de escoamento (runoff) do que setores somente atingidos pelas águas pluviais. Já Dube et al. (2020), em uma análise global do formato de feições erosivas, chamam a atenção para a informação de que as voçorocas tendem a ser mais rasas em setores de clima tropical do que em clima temperado. De acordo com os autores, em zonas tropicais verifica-se precipitação mais alta, fato que propicia uma pedogênese aprimorada, maior estabilidade devido à prevalência de óxidos 
metálicos e argilas cauliníticas e maior cobertura de superfície pela vegetação, fato que justifica a referida morfologia da feição.

Desta forma, além da interação com o clima e as chuvas, entende-se que os fluxos atuantes na superfície terrestre podem interagir com o modelado do relevo. Para Mahmoodabadi e Sajjadi (2016), o transporte de materiais por runoff estará diretamente relacionado à inclinação do terreno. Para os autores, em setores com declividade inferior a $10 \%$, nem todos os materiais destacados serão transportados, sendo que em declives $>10 \%$ se evidenciará uma maior eficácia no transporte de sedimentos. Também Zhang et al. (2019) afirmam que a inclinação do terreno tem relação direta com a erosão laminar, confirmando, em parcelas que variam sua inclinação de $0^{\circ}$ a $25^{\circ}$, um aumento gradual na perda de material a partir da crescente inclinação; sendo que a partir de $20^{\circ}$ a situação se torna crítica e requer atenção ao uso da terra. Ainda, Shen et al. (2016) constataram em ambiente controlado (chuva com intensidade de $50 \mathrm{~mm} \mathrm{~h}^{-1}$ ) um aumento significativo na erosão laminar em $10^{\circ}$ e $15^{\circ}$ (de 7,4 para $13,2 \mathrm{~kg} \mathrm{~m}^{-2} \mathrm{~h}^{-1}$ ), sendo que, comparando os valores com inclinações de $15^{\circ}$ e $20^{\circ}$, as taxas de erosão permaneceram altas, mas com aumento pouco significativo (de 13,2 para 14,4 $\mathrm{kg} \mathrm{m}^{-2} \mathrm{~h}^{-1}$ ). Assim, entende-se que a inclinação do terreno dinamiza o escoamento e esse pode adquirir maior potencialidade erosiva.

Outro fator que pode potencializar a ação erosiva são os fluxos concentrados, os quais podem desencadear impactos negativos na agricultura e nos ecossistemas terrestres através do desenvolvimento de feições erosivas lineares de diferentes dimensões (POESEN et al.,2003; DUBE et al, 2020). Neste contexto, alguns pesquisadores buscaram analisar a influência dos fluxos concentrados sobre os solos em interação com sua cobertura (AL-HAMDAN et al., 2013; NOUWAKPO et al., 2016). Para Nouwakpo et al. (2016), os fluxos concentrados ocorreram de forma mais significativa em áreas de pastagens, com cobertura vegetal escassa, sendo que em setores com cobertura vegetal densa predomina o escoamento laminar; fato ratificado por AlHamdan et al. (2013), ao identificarem, também em áreas de pastagem, que a tensão de cisalhamento exercida sobre solos com $60 \%$ da área total da superfície exposta foi significativamente maior em relação a solos com $25 \%$ de área exposta.

Neste sentido, compreende-se que ação erosiva pela água das chuvas merece atenção, cabendo analisar sua interseção com fatores como a inclinação dos terrenos e uso da terra e, consequentemente, seu manejo, sendo que estes podem interagir de forma a alterar $o$ comportamento dos fluxos superficiais, em especial os fluxos concentrados, os quais, em algumas situações, podem desencadear ou potencializar a ocorrência de feições erosivas. 
Diante deste contexto, um compartimento geomorfológico do relevo paulista que merece atenção são as Cuestas Basálticas, uma vez que a referida unidade apresenta-se sob o domínio de um clima quente e úmido, evidenciando fronts escarpados e tálus inclinado (PENTEADO, 1983; CASSETI, 1994), além de variados padrões de uso da terra agrícola (PINTON, 2016; STEFANUTO; LUPINACCI, 2017a; ANDRADE et al. 2019). Ainda, alguns setores apresentam reduzida aplicação de técnicas agrícolas conservacionistas, fato que potencializa os processos erosivos (STEFANUTO, 2019).

Portanto, tem-se como objetivo deste artigo analisar a interação entre os fluxos acumulados de superfície e as feições erosivas lineares em setor de domínio de Cuestas, buscando ainda compreender a influência da declividade e do uso da terra na dinâmica dos fluxos superficiais.

\section{MATERIAIS E MÉTODO}

Caracterização da área de estudo

A área de estudo constitui-se na alta bacia do córrego Santa Terezinha (Analândia - SP), cujos terrenos integram a bacia do rio Corumbataí (Figura 1). Apresenta 1,9 km², abarcando parte do front e tálus cuestiforme da Serra do Cuscuzeiro. Apesar da dimensão reduzida da área, apresenta composição litológica e pedológica bastante diversificada, constituindo-se em um exemplo da complexidade dos terrenos que ocorrem na região.

Do ponto de vista litológico, registram-se cinco formações geológicas de resistências variadas (IG, 1984), sendo estas: Formação Pirambóia, majoritariamente composta por arenitos médios a muito grossos mal selecionados, conglomerados e clastos centimétricos de argila, características que remetem a sedimentação de rios altamente dinâmicos (rios entrelaçados), apresentando ainda depósitos eólicos subordinados, provenientes de um retrabalhamento dos depósitos fluviais (CÔRTES; PERINOTTO, 2015); Formação Botucatu, depositada em ambiente dominantemente desértico, com intercalações de sedimentos fluviais e lacustres (SCHNEIDER et. al., 1974), sendo caracterizada pela presença constante de estratificação cruzada em grandes cunhas, apresentando paleodunas (ZAINE, 1994); Formação Serra Geral, apresenta uma sequência de rochas vulcânicas, dominantemente composta por lavas basálticas, de composição toleítica e coloração cinza a preta com amígdalas no topo dos derrames, sendo intercalada por delgadas camadas de arenitos intertrapianos (ZAINE, 1994); Formação Itaqueri, pós-basáltica, dotada de arenitos com cimentação argilosa, carapaças ferruginosas, folhelhos e conglomerados (FACINCANI, 2000); e Formação Santa Rita do Passa Quatro, atrelada aos depósitos cenozóicos, 
sendo formada por sedimentos de areias finas, compostos majoritariamente por quartzo e apresentando de $77 \%$ a $94 \%$ de areia (FACINCANI, 2000).

Figura 1 - Localização da área de estudo.

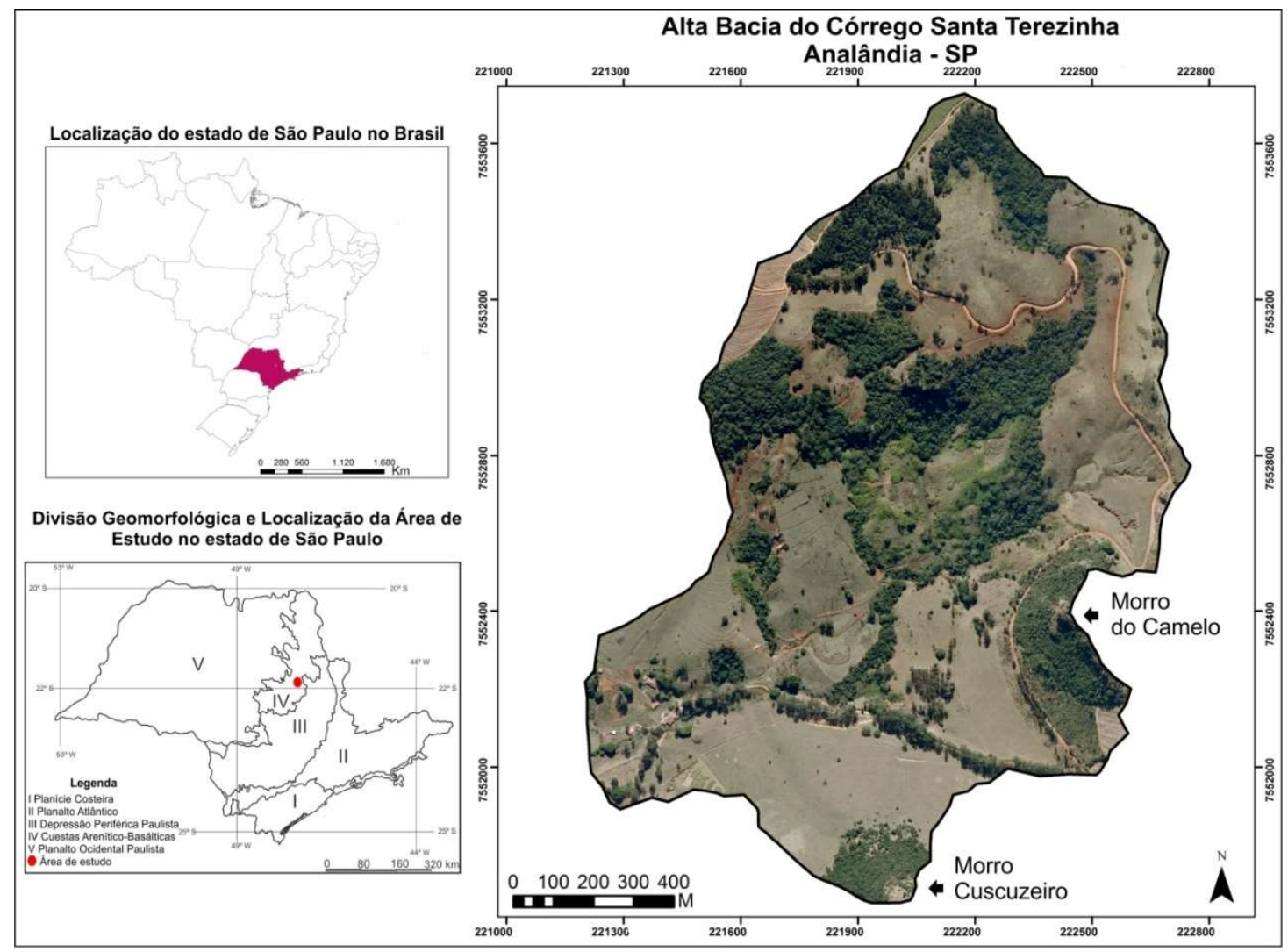

Fonte: Stefanuto (2019)

Em relação aos solos, o setor apresenta duas classes típicas de solos e três classes associadas (KOFFLER et al., 1992). No que corresponde às classes típicas, foram identificados Argissolos Vermelho-Amarelo Distróficos da Unidade Santa Clara, os quais apresentam abundância de cascalhos e calhaus no horizonte A e B, espessura do horizonte $\mathrm{A}+\mathrm{B}$ inferior a $150 \mathrm{~cm}$, elevado teor de minerais primários facilmente intemperizáveis e material de origem vinculado às fáceis conglomeráticas da Formação Itaqueri (OLIVEIRA; PRADO, 1984); e Latossolos VermelhoAmarelo Álicos da Unidade Coqueiro, os quais são classificados com textura média, horizonte B apédico ou com estrutura subangular fraca, com teor de argila inferior a $20 \%$ e predominância de areia grossa sobre a fina (OLIVEIRA; PRADO, 1984). Já em relação às classes associadas, identifica-se uma primeira associação entre Neossolos Litólicos pouco evoluídos, com horizonte A assentado diretamente sobre um horizonte $\mathrm{C}$ ou $\mathrm{Cr}$ ou sobre material com mais de $90 \%$ de seu volume constituído por fragmentos rochosos (EMBRAPA, 2006), e Nitossolos Eutróficos ou Distróficos da Unidade Estruturada, com textura argilosa ou muito argilosa, grande homogeneidade 
vertical em cor, espessura do solum superior a $120 \mathrm{~cm}$ e horizonte B3 podendo apresentar estrutura fraca e friável (OLIVEIRA; PRADO, 1984). Uma segunda associação ocorre entre Argissolos Vermelhos Distróficos da Unidade Barão Geraldo, os quais apresentam textura muito argilosa ou argilosa, teor de areia grossa inferior a 20\% e horizonte B2 apédico, com estrutura subangular fraca e consistência friável ou muito friável (OLIVEIRA; PRADO, 1984), e Nitossolos Eutróficos ou Distróficos da Unidade Estruturada. Por fim, uma terceira associação ocorre entre Latossolos Vermelho-Amarelo Álicos da Unidade Itororó, que possuem horizonte A proeminente, textura do horizonte B argilosa ou muito argilosa, em função do material de origem ser suprabasáltico, constituindo solos muito profundos e muito friáveis (OLIVEIRA; PRADO, 1984), e Plintossolos Pétricos Concrecionários, que são compostos por material mineral, no qual se identificam horizontes litoplínticos ou concrecionários, sendo pouco profundos, porém, com mais de 30\% de terra fina argilosa ou muito argilosa, a qual não apresenta crescimento substancial ao longo do perfil (OLIVEIRA; PRADO, 1984).

Em relação ao regime pluviométrico, Analândia apresenta a ocorrência de chuvas, em média, durante 82 dias do ano, totalizando média pluviométrica anual de 1.272,7 mm (BRINO, 1973). Ainda, o mês mais chuvoso constitui-se em janeiro, no qual o índice pluviométrico ultrapassa $215 \mathrm{~mm}$, tendo como mês mais seco julho ou agosto, com média pluviométrica que alcança os 30,9 mm (BRINO, 1973).

Por fim, em relação ao uso e ocupação da terra, a maior parte da bacia constitui-se em pastagens destinadas à pecuária desde 1962, com parte do front cuestiforme recoberto por vegetação nativa. Ainda, nos últimos 10 anos, registrou-se uma evolução significativa de setores ocupados pela espécie arbustivo-arbórea Tecoma stans, a qual é classificada por Pedrosa-Macedo e Bredow (2004) como espécie invasora (STEFANUTO, 2019).

Elaboração da Carta de Fluxo Acumulado do Escoamento Superficial

O modelo digital de elevação (MDE) constitui-se em um importante modelo de superfície para formulação de produtos para cartografia dos fluxos superficiais, uma vez que os mesmos evidenciam a drenagem a montante de cada célula, as formas das vertentes e as características da declividade do terreno (MORAES et al., 2014). Ainda, o MDE se caracteriza pela formação de uma matriz (MORAES et al., 2014), a qual, submetida a algoritmos específicos, pode fornecer dados referentes a área de contribuição de fluxo $\left(\mathrm{m}^{2}\right.$ ou $\left.\mathrm{km}^{2}\right)$ de cada célula da matriz a jusante de uma determinada célula central, fator que permite a formulação da carta de fluxos acumulados (FONTES, 2009). 
Desta forma, inicialmente, foi desenvolvido no ArcGis 10.1 um MDE a partir de base cartográfica obtida por meio das folhas Serra da Estrela (SF-23-Y-A-I-2-NO-E) e Analândia I (SF23-Y-A-I-2-NO-F), produzidas pelo Instituto Geográfico Cartográfico do Estado de São Paulo (IGCSP) em 1979, em escala de 1:10.000, com equidistância das curvas de nível de 5 m. Para tal, utilizou-se a ferramenta Topo to Raster e as informações das curvas de nível e dos pontos cotados. Posteriormente, o MDE foi adicionado ao ArcView 3.0, sendo submetido a uma sequência de procedimentos disponíveis na ferramenta Preparation. Primeiramente, foi aplicada ao MDE a função Felling Sinks, a qual garantiu o preenchimento de depressões do terreno; a seguir, os produtos da função anterior foram submetidos à opção Flow Direction, para obtenção da direção do fluxo; e, por fim, foi aplicado o comando DEM Correction para correção de possíveis erros. Para a formulação da carta, foi utilizado o algoritmo MD-Multiple Flow (MORAES et al., 2014), adicionando ao campo DEM o produto proveniente da correção e à opção Weight o produto com as direções de fluxo. A partir do processamento, a carta de fluxo acumulado foi gerada, sendo posteriormente exportada para o ArcGis para ajustes nas classes.

A partir de testes na função symbology e a verificação da correspondência de acumulação de fluxo de acordo com as curvas de nível e as concavidades e convexidades de vertentes, estabeleceram-se 7 classes de fluxo acumulado. Buscando apresentar as classes em $\mathrm{m}^{2}$ (MATHIAS, 2016), atribuiu-se o valor de $25 \mathrm{~m}^{2}$ a cada pixel, uma vez que MDT foi gerado a partir da equidistância de 5 metros das curvas de nível. Assim, foram definidos, em $\mathrm{m}^{2}$, os seguintes intervalos de classe: 25-625; 625,1-2.500; 2.500,1-12.500; 12.500,1-25.000; 25.000,1-50.000; de $50.000,1-250.000 ; \mathrm{e}>250.000,1$.

Quantificação da área ocupada pelas feições erosivas lineares

Os dados das feições erosivas lineares (sulcos erosivos, ravinas e voçorocas) utilizados para esta pesquisa são provenientes da Carta de Feições Erosivas Lineares, produzida por Stefanuto (2019), na qual constam feições mapeadas nos anos de 1962, 1988, 2010 e 2019. Desta forma, para a quantificação da área ocupada pelas feições erosivas em cada classe de fluxo acumulado, atribuise um buffer às erosões delimitadas como linha (sulcos e ravinas); as voçorocas foram mapeadas desde o inicio como polígonos. Assim, atribuiu-se um buffer de $10 \mathrm{~cm}$ aos sulcos erosivos e um buffer de $50 \mathrm{~cm}$ as ravinas, conforme medidas observadas em campo. A quantificação da área ocupada pelas feições erosivas em relação ao fluxo acumulado de superfície foi feita através das ferramentas Clip e Caculate Geometry, uma vez que as informações de fluxo foram convertidas para o formato polígono. Por fim, os dados provenientes da quantificação foram exportados ao 
Excel para aplicação da densidade normalizada, na qual se dividiu a área ocupada pela feição erosiva pela área total de cada classe de fluxo. Esse procedimento visou eliminar o efeito da dimensão das classes. Ainda, os valores se apresentaram reduzidos; assim, buscando melhorar a interpretação dos dados e destacar as variações numéricas, tais valores foram submetidos a um coeficiente com intervalo de $0-1$. O valor máximo, representado por 1 , indicou a classe de maior área ocupada por determinada feição erosiva.

\section{RESULTADOS}

Em relação à distribuição espacial do fluxo acumulado na bacia hidrográfica analisada (Figura 2), identificaram-se classes mais elevadas nas vertentes do setor sul, as quais estão associadas à dinâmica de sopé dos morros testemunho da área de estudo e se estendem até o canal principal da bacia. Já nos setores central e norte, identificaram-se classes mais baixas, sendo estas áreas correspondentes, majoritariamente, ao setor do front cuestiforme. Ainda, as três principais classes de fluxo acumulado, em área, foram de $25 \dashv 625$, de 625,1 $\dashv 2.500$, e de 2.500,1 $\dashv 12.500$, ocupando, respectivamente, $12 \%, 29,9 \%$ e 34,1\% da bacia. Já as classes mais elevadas, de 25.000,1 $\dashv 50.000$, de 50.000,1 $\dashv 250.000$ e $\geq 250.000,1$, ocupam menor área, com, respectivamente, $6 \%$, $4,7 \%$ e $2,9 \%$.

Ainda, ao comparar a disposição das feições erosivas lineares em relação às classes de fluxo acumulado (Tabela 1), identificou-se uma distribuição equilibrada da área ocupada por sulcos e de ravinas. Os índices de concentração máxima ocorreram na classe 3 (sulcos erosivos) e na classe 4 (ravinas), demonstrando não ocorrer uma relação direta entre fluxos elevados e feições erosivas do tipo sulco e ravina, fato ratificado pelo reduzido coeficiente identificado na classe 7 em ambas as feição (0.545 e 0.522, respectivamente). Já as feições do tipo voçoroca apresentaram concentração máxima na classe 6 e valores mais baixos nas demais. Destaca-se ainda que a ocorrência dos tipos de feições erosivas em relação ao fluxo tem caráter ascendente de acordo com seu grau de desenvolvimento, ou seja, os sulcos, feição que caracteriza o primeiro estágio de desenvolvimento da erosão linear, apresenta concentração máxima na classe 3, as ravinas, estágio intermediário, na classe 4 e as voçorocas, estágio mais avançado, na classe 6. 
Figura 2 - Carta de Fluxo Acumulado do Escoamento Superficial da Alta Bacia do Córrego Santa Terezinha - Analândia (SP).

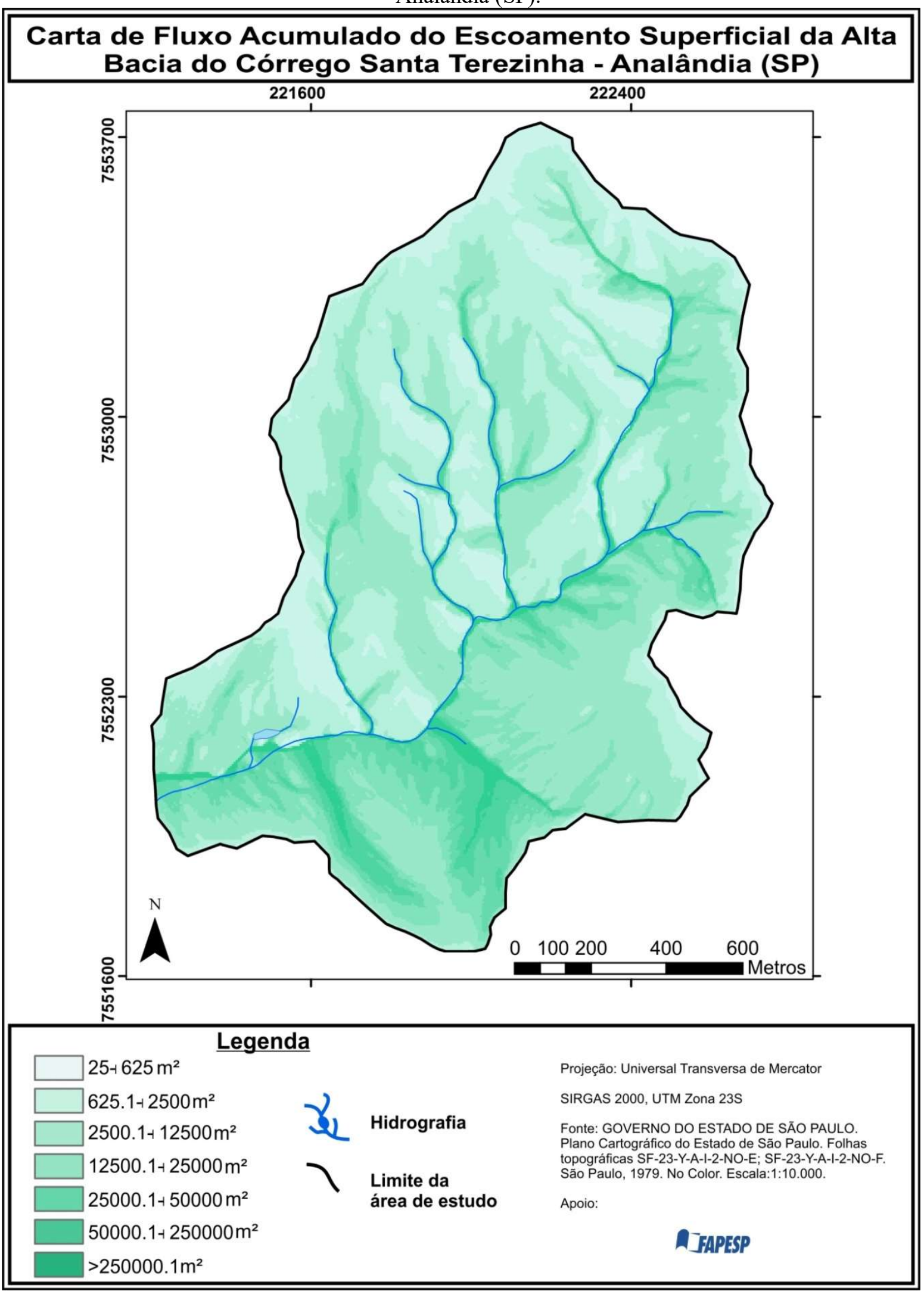


Tabela 1 - Coeficiente de 0-1 da área ocupada por feições erosivas lineares em cada classe da carta de fluxo acumulado. Valores das classes em m²: classe 1 (25-625); classe 2 (625,1-2.500); classe 3 (2.500,1-12.500); classe 4 (12.500,1-25.000); classe $5(25.000,1-50.000)$; classe $6(50.000,1-250.000)$ e classe 7

\begin{tabular}{|c|c|c|c|c|c|c|c|}
\hline Feições Erosivas & Classe 1 & Classe 2 & Classe 3 & Classe 4 & Classe 5 & Classe 6 & Classe 7 \\
\hline Sulcos Erosivos & 0.681 & 0.727 & 1 & 0.818 & 0.772 & 0.954 & 0.545 \\
\hline Ravinas & 0.921 & 0.736 & 0.815 & 1 & 0.473 & 0.684 & 0.552 \\
\hline Voçorocas & 0.373 & 0.136 & 0.294 & 0.168 & 0.147 & 1 & 0.089 \\
\hline
\end{tabular}

\section{DISCUSSÃO}

Em um primeiro momento, compreende-se que a bacia hidrográfica estudada apresenta, em grande parte de sua extensão, fluxos acumulados com valores pouco elevados em relação ao universo da área de estudo. Neste sentido, entendendo que o setor centro-norte é caracterizado pelo front cuestiforme, verifica-se a atuação de drenagens anaclinais, sendo estas típicas em tais setores (CASSETI, 1994). Os referidos cursos fluviais têm suas nascentes associadas ao front, fato que pode garantir alta energia gravitacional às águas em função da inclinação do terreno, possibilitando o entalhamento dos rios e o escavamento de vales encaixados, identificados na Serra do Cuscuzeiro por outras pesquisas (PINTON, 2016; STEFANUTO; LUPINACCI, 2017b). Tais vales podem apresentar vertentes pouco extensas e, consequentemente, no contexto desta pesquisa, classes de fluxo acumulado pouco elevadas. Já o setor sul é marcado por longas vertentes côncavas, as quais apresentam declive em direção a extensos vales pluviais, fato que, a partir da técnica de mapeamento aplicada neste artigo, a qual quantifica a área de contribuição de fluxo de cada célula a jusante de uma determinada célula central (FONTES, 2009), justifica tais vertentes apresentarem valores de fluxo acumulado elevados.

Ainda, em relação à interação entre fluxos e feições erosivas, algumas pesquisas (POESEN et al.,2003; DUBE et al, 2020) destacam que o fluxo, quando concentrado, pode desencadear impactos negativos nos ecossistemas, fato que leva ao desencadeamento de feições erosivas; sendo neste contexto possível prever uma relação linear entre aumento do fluxo e a maior ocorrência de feições. No entanto, tal fato não se ratifica nos dados de sulcos e ravinas desta pesquisa (Tabela 1), se caracterizando em uma possível resposta não linear deste sistema. Assim, buscando analisar tal conjunto de dados, identificou-se que os valores que compõe as classes de fluxo da área estudada são muito mais elevados do que os registrados em outros estudos, que utilizaram a mesma técnica de mapeamento em setores de cuesta (MATHIAS, 2016), na Depressão Periférica Paulista (MORAES et al., 2014) e no Planalto Ocidental Paulista (THOMAZINI, 2018). Desta forma, em 
um contexto erosivo mais amplo, apresentado pela bibliografia (MORAES et al., 2014; MATHIAS, 2016; THOMAZINI, 2018), verifica-se que os sulcos e ravinas identificados nesta pesquisa ocorrem em setores de fluxo acumulado elevado; no entanto outras variáveis, sendo algumas apresentadas nesta seção, também contribuem para ocorrência de tais feições erosivas.

Já em relação às voçorocas, os dados evidenciam uma concentração marcante na classe 6, fato que pode ser associado à morfologia e à dimensão destas feições. As voçorocas apresentam definições diversas, no entanto, compreende-se, neste artigo, voçoroca como uma feição erosiva linear com formato de vale mais alargado do que as ravinas, atestando talude íngreme (FURLANI, 1980; GOUDIE, 2004; AUGUSTIN; ARANHA, 2006; SOIL SCIENCE SOCIETY OF AMERICA, 2008). Ainda, de acordo com Stefanuto e Lupinacci (2019), as voçorocas do setor apresentam grandes dimensões, uma vez que em 2010 somaram $36.861 \mathrm{~m}^{2}$, sendo $14.635 \mathrm{~m}^{2}$ pertencentes a uma única feição posicionada no setor leste da bacia (Figura 3). Neste sentido, compreende-se que tais feições erosivas apresentam potencial de concentração dos fluxos superficiais, fato que se exemplifica nos dados da Tabela 1. Assim, considera-se importante monitorar o desenvolvimento de tais feições erosivas, uma vez que também recebem fluxos de amplas áreas a montante, fato que se constitui em um desafio do ponto de vista de aplicação de técnicas de mitigação.

Considera-se também a declividade e o uso e ocupação da terra como variáveis importantes na análise e discussão dos fluxos superficiais do setor analisado (AL-HAMDAN et al., 2013; SHEN et al., 2016). Como apresentado, a bacia hidrográfica situa-se em uma área de domínio cuestiforme, fator que agrega importância significativa à inclinação do terreno. Neste sentido, algumas pesquisas destacam a ocorrência de erosão em vertentes com inclinação superior a $20^{\circ}$ (ZHANG et al,. 2019), já outras análises (SHEN et al., 2016) chamam a atenção para setores entre $10^{\circ}$ e $15^{\circ}$ de inclinação, sendo ainda, destacadas por Mahmoodabadi e Sajjadi (2016) áreas com mais de 10\% (aproximadamente $6^{\circ}$ ) de inclinação. Desta forma, a partir da Carta de Declividade da área de estudo (STEFANUTO, 2019), verificou-se que alguns setores da bacia hidrográfica apresentam mais de $27^{\circ}$ (front da cuesta) de inclinação, fato que conduz esta análise para compreensão que os fluxos atuantes no setor de estudo não apresentam somente relação com a extensão das vertentes, mas podem também apresentar uma estreita relação com a inclinação, a qual, em graus elevados como do front da cuesta, podem adicionar, até mesmo em vertentes pouco extensas, energia cinética relevante do ponto de vista erosivo, podendo ser esta questão um caminho para o entendimento da relação entre os sulcos e ravinas e as classes de fluxos. 
Figura 3 - Voçoroca no setor leste da área de estudo.

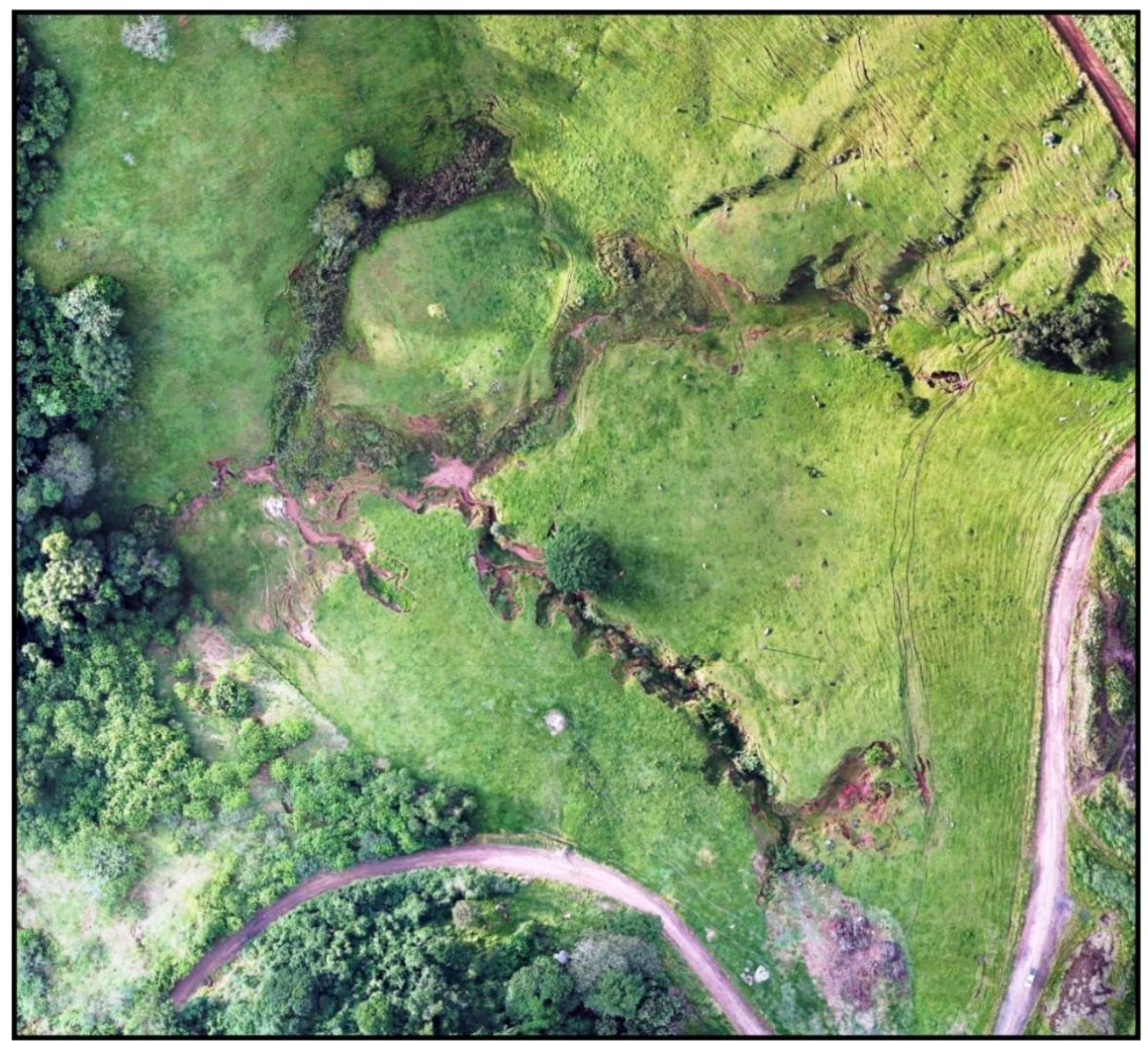

Fonte: Stefanuto (2019)

Neste sentido, Stefanuto (2019), em estudo desenvolvido na mesma bacia hidrográfica deste artigo, constatou, a partir da densidade normalizada entre feições erosivas lineares (sulcos, ravinas e voçorocas) e as classes de declividade, uma maior ocorrência de sulcos erosivos nas seguintes classes $<2 \%\left(<1,27^{\circ}\right)$ e $12-30 \%\left(7,6^{\circ}\right.$ a $\left.18,5^{\circ}\right)$, de ravinas em $12-30 \%$ e $30-45 \%\left(18,5^{\circ}\right.$ a $\left.26,91^{\circ}\right)$ e de voçorocas em 30-45\% e $>45 \%\left(>26,91^{\circ}\right)$. Assim, verifica-se que as feições erosivas em estágio mais avançado apresentam relação espacial direta com os setores de maior declividade, fomentando a discussão apresentada; no entanto, parte dos dados de ravinas e sulcos não ratificam tal relação. Neste sentido, é importante destacar uma possível relação de vizinhança para o desenvolvimento e evolução de algumas ravinas, uma vez que os fluxos superficiais podem ganhar maior energia em setores com inclinação acentuada (30-45\% e >45\%), no entanto a atuação erosiva pode ocorrer em áreas vizinhas com menor inclinação (12-30\%). Já os sulcos erosivos variam a partir do uso da terra (STEFANUTO; LUPINACCI, 2017c), uma vez que tais mudanças pressupõem diferentes coberturas vegetais e práticas agropecuárias. 
Neste sentido, vale atenção ao uso da terra caracterizado por pastagens, o qual, em 2019, ocupava 43,1\% da bacia hidrográfica analisada (STEFANUTO, 2019). Tais áreas merecem atenção em relação à atuação dos fluxos concentrados, uma vez que setores de pastagem, com cobertura vegetal escassa, podem potencializar a ação do fluxo e contribuir para o desenvolvimento erosivo (AL-HAMDAN et al., 2013; NOUWAKPO et al., 2016). Neste sentido, é importante destacar que no setor de estudo as pastagens voltadas para pecuária apresentam baixo grau de manutenção, conforme constatado in loco, fato que pode propiciar descontinuidade na cobertura vegetal, originando, consequentemente, setores preferenciais para o escoamento. Ainda, identificou-se a roçadura como a principal técnica de manutenção empregada, não registrando outras técnicas conservacionistas, como a manutenção de curvas de nível, a adubação e a rotação de pastagens com uma taxa de lotação específica (Figura 4).

Figura 4 - Curvas de nível desmanteladas por sulcos e ravinas em função da ausência de manutenção no setor sudoeste da área de estudo, em janeiro de 2018.

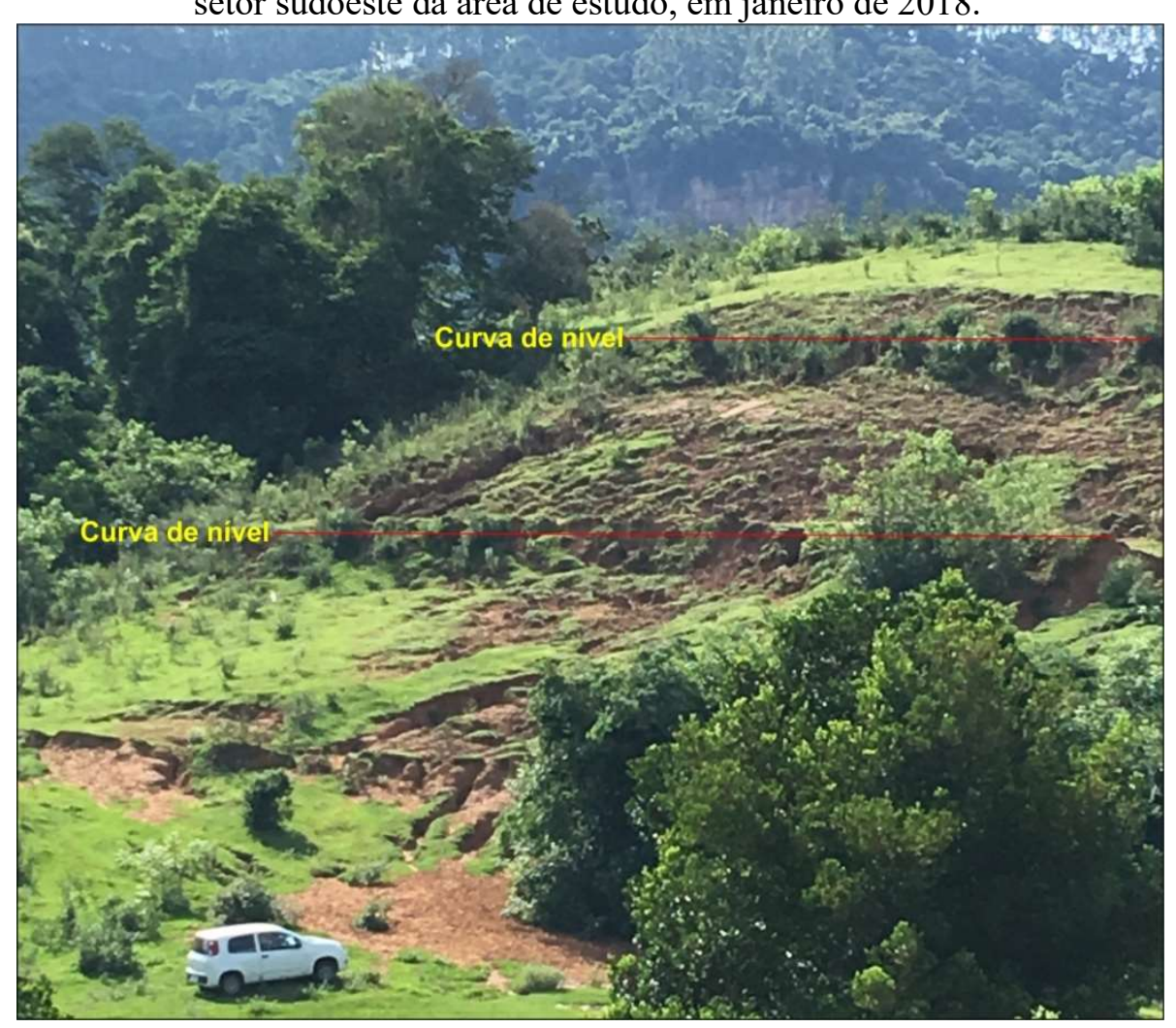

Fonte: Stefanuto (2019).

Desta forma, é importante ponderar o uso da terra neste tipo de análise, uma vez que a carta de fluxo acumulado não considera os possíveis obstáculos ou áreas preferenciais de escoamento geradas pela cobertura da terra na extensão das vertentes. Tal discussão também representa uma perspectiva para o entendimento da não linearidade dos sulcos e ravinas em relação às classes de fluxos. 


\section{CONSIDERAÇÕES FINAIS}

A partir da análise comparativa entre feições erosivas lineares e fluxos acumulados de superfície, identificou-se que os sulcos erosivos e as ravinas apresentam-se mais dispersos em relação às classes de fluxo, uma vez que o desenvolvimento de tais feições pode apresentar contribuições significativas da declividade e do uso e ocupação da terra. Já as voçorocas se apresentam concentradas na segunda maior classe de fluxo (classes 6), questão a qual pode estar relacionada as dimensões das feições e ao fluxo de amplas áreas a montante. Por fim, destaca-se a importância de considerar a influência da declividade e do uso da terra na análise de dados de fluxo acumulado, uma vez que determinados declives contribuirão para a ocorrência de fluxo com energia gravitacional relevante e alguns usos determinarão caminhos específicos e, consequentemente mais concentrados, para os fluxos superficiais.

\section{AGRADECIMENTOS}

À Fundação de Amparo à Pesquisa do Estado de São Paulo - FAPESP, pelo financiamento dos projetos no 2016/25399-1 e 2018/09746-9, e à Coordenação de Aperfeiçoamento de Pessoal de Nível Superior - Brasil (CAPES), Código de Financiamento 001.

\section{REFERÊNCIAS BIBLIOGRÁFICAS}

AUGUSTIN, C. H. R. R.; ARANHA, P. R. A. A ocorrência de voçorocas em Gouveia, MG: Características e Processos Associados. Geonomos. n.14, p.75-86, 2006.

AL-HAMDAN, O.Z., PIERSON, F.B., NEARING, M.A., WILliAMS, C.J., STONE, J.J., KORMOS, P.R., BOLL, J., WELTZ, M.A. Risk assessment of erosion from concentrated flow on rangelands using overland flow distribution and shear stress partitioning. Transactions of the ASABE, v. 56, n. 2, p. 539-548, 2013.

ANDRADE, R. V. de.; LUPINACCI, C. M.; STEFANUTO, E. B. Análise do uso e ocupação da terra em faixa de proteção no reverso da cuesta de Botucatu (SP). In: SIMPÓSIO BRASILEIRO DE GEOGRAFIA FÍSICA APLICADA, XVIII, 2019, Fortaleza - CE. Anais... Fortaleza: XVIII SBGFA, 2019. 1-12. Disponível em: <http://www.editora.ufc.br/catalogo/28-geografia/982geografia-fisica-e-as-mudancas-globais>. Acesso em: 22 de janeiro de 2020

BRINO, W. C. Contribuição à definição climática da Bacia do Corumbataí e adjacências (SP), dando ênfase à caracterização dos tipos de tempo. 1973. 119 f. Tese (Doutorado em Geografia) Faculdade de Filosofia, Ciências e Letras de Rio Claro, Rio Claro, 1973. 
CASSETI, V. Elementos de Geomorfologia. Goiânia: Editora da UFG, 1994.

CÔRTES, R. A. P.; PERINOTTO, A. J. J. Fácies e associação de fácies da Formação Piramboia na região de Descalvado (SP). Geologia USP. Série Científica, v. 15, n. 3-4, p. 23-40, 2015.

DUBE, H. B.; MUTEMA, M.; MUCHAONYERWA, P.; POESEN, J.; CHAPLOT, V. A global analysis of the morphology of linear erosion features. Catena, v. 190, p. 104542, 2020.

EMPRESA BRASILEIRA DE PESQUISA AGROPECUÁRIA - EMBRAPA. Sistema Brasileiro de Classificação dos Solos. Brasília, 2006.

EUROPEAN ACADEMIES SCIENCIE ADVISORY COUNCIL - EASAC. Extreme weather events in Europe. 2018a. Disponível em: < https://easac.eu/publications/details/extreme-weatherevents-in-europe/>. Acesso em: 12 de fevereiro de 2020.

EUROPEAN ACADEMIES SCIENCIE ADVISORY COUNCIL - EASAC. Opportunities for soil sustainability in Europe. Germany: German National Academy of Sciences Leopoldina, 2018b. Disponível em: < https://easac.eu/publications/details/opportunities-for-soil-sustainabilityin-europe/>. Acesso em: 12 de fevereiro de 2020.

FACINCANI, E. M. Morfotectônica da depressão periférica paulista e cuesta basáltica: regiões de São Carlos, Rio Claro e Piracicaba, SP. 2000. 222 f. Tese (Doutorado em Geologia Regional) - Instituto de Geociências e Ciências Exatas, Universidade Estadual Paulista, Rio Claro, 2000.

FONTES, N. Proposta metodológica para planejamento de sistemas de espaços livres: Ribeirão Preto - SP. 2009. 193 f. Tese (Doutorado em Geografia) - Instituto de Geociências e Ciências Exatas, Universidade Estadual Paulista, Rio Claro, 2009.

FOOD AND AGRICULTURE ORGANIZATION OF THE UNITED NATIONS - FAO. Status of the Word's Soil Resources. Roma, 2015

FURLANI, G. M. Estudo geomorfológico das boçorocas de Casa Branca - São Paulo. 1980. 379f. Dissertação. Departamento de Geografia (FFLCH), São Paulo, 1980.

GOUDIE, A. S. Encyclopedia of Geomorphology (Volume 1). London and New York: Routledge, 2004

GUERRA, A. T.; GUERRA, A. J. T. Novo Dicionário Geológico-Geomorfológico. 8 ed. Rio de Janeiro: Bertrand Brasil, 2010.

INTITUO GEOGRÁFICO CARTOGRÁFICO DO ESTADO DE SÃO PAULO - IGCSP. Plano Cartográfico do Estado de São Paulo. São Paulo: Governo do Estado de São Paulo,1979. No color. Escala: 1:10.000. 
INSTITUTO GEOLÓGICO - IG. Folha Geológica de Corumbataí (SF-23-Y-A-I-2): Formações Geológicas de Superfície. São Paulo: Instituto Geológico, 1984. Escala 1:50.000.

KOFFLER, N. F.; MACHADO, M. L. de. A.;DAROS, E.; PROCHNOW, E. A. Solos da bacia do Rio Corumbataí. Rio Claro: Departamento de Cartografia e Análise da Informação Geográfica Instituto de Geociências e Ciências Exatas, Universidade Estadual Paulista, 1992. Escala: 1:50.000. MAHMOODABADI, M.; SAJJADI, S. A. Effects of rain intensity, slope gradient and particle size distribution on the relative contributions of splash and wash loads to rain-induced erosion. Geomorphology, v. 253, p. 159-167, 2016.

MORAES, I. C.; CONCEIÇÃO, F. T. da; LUPINACCI, C. M.; MORUZZI, R. B. Comparação de Metodologias na Definição de Fluxos Acumulados a Partir de Modelos Digitais de Elevação do Terreno Aplicado a Suscetibilidade de Inundações. Revista Brasileira de Recursos Hídricos. v.19, n.2, 223-235, 2014

MARZEN, M., ISERLOH, T., DE LIMA, J.L.M.P., FISTER, W., RIES, J.B. Impact of severe rain storms on soil erosion: Experimental evaluation of wind-driven rain and its implications for natural hazard management. Sci. of the Total Environ., v. 590-591, p. 502-513, 2017.

MATHIAS, D. T. Contribuição Metodológica para o Diagnóstico da Dinâmica Erosiva Linear e seu Prognóstico Evolutivo visando subsidiar Projetos de Recuperação. 2016. 178 f. Tese (Doutorado em Geografia). Faculdade de Ciências e Tecnologias, Universidade Estadual Paulista UNESP, Presidente Prudente, 2016.

NOUWAKPO, S.K., WILliAMS, C.J., AL-HAMDAN, O.Z., WELTZ, M.A., PIERSON, F., NEARING, M. A review of concentrated flow erosion processes on rangelands: Fundamental understanding and knowledge gaps. International Soil and Water Conservation Res. v.4, n.2, p. 75-86, 2016.

OLIVEIRA, J. B. de; PRADO, H. do. Levantamento Pedológico Semidetalhado do Estado de São Paulo: Quadrícula de São Carlos - II Memorial Descritivo. Boletim Técnico No 98. Campinas: Instituto Agronômico, 1984.

PEDROSA-MACEDO, J. H.; BREDOW, E. A. Princípios e rudimentos do controle biológico de plantas: coletânea. Curitiba: [s.n.], 2004.

PENTEADO, M. Fundamentos de Geomorfologia. 3 ed. Rio de Janeiro: IBGE, 1983

PINTON, L. G. Evolução dos processos morfogenéticos em relevo cuestiforme: a bacia do Córrego do Cavalheiro - Analândia (SP). 2016. 129 f. Tese (Doutorado em Geografia) Programa de Pós-Graduação em Geografia, Universidade Estadual Paulista, Rio Claro, 2016. 
POESEN, J.; NACHTERGAELE, J.; VERSTRAETEN, G.; VALENTIN, C. Gully erosion and environmental change: Importance and research needs. Catena, v. 50, p.91-133, 2003

SHEN, H.; ZHENG, F.; WEN, L.; HAN, Y.; HU, W. Impacts of rainfall intensity and slope gradient on rill erosion processes at loessial hillslope. Soil and Tillage Res., v. 155, p. 429-436, 2016.

SCHNEIDER, R. L. et. al. Revisão estratigráfica da Bacia do Paraná. In: CONGRESSO BRASILEIRO GEOLOGIA. 28. 1974, Porto Alegre. Anais... Porto Alegre, 1974, p. 41-65.

SOIL SCIENCE SOCIETY OF AMERICA. Glossary of Soil Scienci Terms. Madison: Soil Scienci Society of America, 2008.

STEFAnUtO, E. B. Análise da Dinâmica Erosiva Linear e seu Potencial Evolutivo em Ambiente Agrícola. 2019. 123 f. Dissertação (Mestrado em Geografia). Programa de PósGraduação em Geografia, Universidade Estadual Paulista, Rio Claro, 2019.

STEFANUTO, E. B.; LUPINACCI, C. M. Atuação dos sistemas de forçamento nos sistemas terrestres a partir da ação antrópica. In: SIMPÓSIO NACIONAL DE GEOGRAFIA FÍSICA APLICADA E CONGRESSO NACIONAL DE GEOGRAFIA, 17 e 1. 2017, Campinas. Anais [...] Campinas: UNICAMP, 2017a. p. 6151-6161.

STEFANUTO, E. B.; LUPINACCI, C. M. A simbologia geomorfológica adaptada para mapeamentos de feições do relevo desenvolvidos em ambiente SIG. In: CONGRESSO BRASILEIRO DE CARTOGRAFIA E EXPOSICARTA, 27 e 26. 2017, Rio de Janeiro. Anais [...] Rio de Janeiro: SBC, 2017b. p. 1289-1293.

STEFANUTO, E. B.; LUPINACCI, C. M. Análise da dinâmica erosiva presente no setor cuestiforme de Analândia (SP). In: ENCONTRO NACIONAL DA ANPEGE - ENANPEGE, 12, 2017, Porto Alegre - RS. Anais... Porto Alegre: ANPEGE, 2017c. p.11625-11636.

STEFANUTO, E. B.; LUPINACCI, C. M. Avaliação das Características Ambientais de Ocorrências das Feições Erosivas Lineares nos Limites Depressão-Cuesta - Analândia (SP). Caminhos de Geografia, v. 20, n. 70, p. 367-384, 2019.

THOMAS, J.; JOSEPH, S.; THRIVIKRAMJI, K. P. Estimation of soil erosion in a rain shadow river basin in the southern Western Ghats, India using RUSLE and transport limited sediment delivery function. International Soil and Water Conservation Res., v. 6, n. 2, p. 111-122, 2018. THOMAZINI, L. S. Proposta metodológica de orientação à expansão urbana sob o viés geomorfológico: o caso da bacia do Córrego Pau D’alho, Bauru (SP). 2018. 158 f. Tese 
(Doutorado em Geografia) - Instituto de Geociências e Ciências Exatas, Universidade Estadual Paulista, Rio Claro, 2018.

ZAINE, J. E. Geologia da Formação Rio Claro na folha Rio Claro (SP). 1994. 98 f. Dissertação (Mestrado em Geologia Regional) - Instituto de Geociências e Ciências Exatas, Universidade Estadual Paulista, Rio Claro, 1994.

ZHANG, J.; YANG, M.; DENG, X.; LIU, Z.; ZHANG, F. The effects of tillage on sheet erosion on sloping fields in the wind-water erosion crisscross region of the Chinese Loess Plateau. Soil and Tillage Res., v. 187, p. 235-245, 2019. 